Research article Available online www.ijsrr.org

ISSN: 2279-0543

International Joumal of Scientific Research and Reviervs

\title{
Charge Oscillator
}

\author{
Sahu Kumar Pankaj ${ }^{1 *}$ \\ ${ }^{1}$ Department of physics, St Paul College, Ranchi-834001, Jharkhand, INDIA \\ http://doi.org/10.37794/IJSRR.2019.8414
}

\begin{abstract}
An Oscillator is used for accelerating charged particles, so that they acquire energy large enough to carry out the nuclear reactions. In fig 1.1 the electric field which is applied is directly proportional to the radius of circular motion. By increasing the electric field in proportion, the kinetic energy of the positive ions also increases. A magnetic field is applied plane to the paper and perpendicular to the velocity of positive ion. The motion of the positive ion will be a combination of the circular motion and straight path. A metallic plate is used which applied electric field to the positive ion.In these charged oscillator DC voltage are used. It is suitable for accelerating heavy charged particles such as proton positive ions. It is based on the principal that $\mathrm{E}$ is directly proportional to the radius of positive ion.
\end{abstract}

KEYWORDS: Magnetic field, Charge, Electric field, Proton, Oscillator

\section{* Corresponding author}

\section{Pankaj Kumar Sahu}

Department of physics

St Paul College,

Ranchi-834001, Jharkhand, INDIA.

Email: $\underline{\text { sahupk1905@gmail.com , Mob No - } 8409225906}$ 


\section{INTRODUCTION}

A particle accelerator is a machine that uses electromagnetic fields to propel charged particle to very high speed and energies and to contain them in well defined beams ${ }^{1}$. Particle accelerator are usually complex and expensive machine. The accelerated particle are generally made to collide with other particle. The basic idea of a synchrotron was stated by Oliphant. L.W Alvarez built the first high-energy (32Mev) proton linear accelerator ${ }^{2}$. In 1948, Ginzton, Hansen and Kennedy reported the construction, completed in early 1947, of a $0.9 \mathrm{~m}$ long, $1.5 \mathrm{Mev}$ electron linear accelerator that used a $3 . \mathrm{GHz}$ magnetron as a RF power ${ }^{3}$. As early as in 2005 and 2006 there were published advanced consideration on the photon collider at ILC ${ }^{4}$. Editorial series on accelerator science and technology has been recently published in its 50 volume, now within the EU ARIES H2020 project ${ }^{5,6}$.

Cyclotron is one of the type of particle accelerator invented by Ernest O. Lawrence in 19291930 at the University of California, Berkeley. It accelerate the charged particle outward from the center along a spiral path ${ }^{7}$.

\section{LITERATURE REVIEW}

In Modern ABC, the author Satish K Gupta discuss about charge oscillator. The charge oscillator made by Lawrence is wonderful device but this device work only on AC voltage. When we applied DC voltage it does not work and it is a main drawback. To overcame this problem I came with new idea and also with new principal. In my charge, oscillator dees are not required.

\section{DISCUSSION}

It is based on the principal that when we increase an electric field in a proportion the radius of a positive ion increases. It is suitable for accelerating heavy charged particle. The whole apparatus is placed between the two poles of a strong electromagnet NS as shown in fig 1.1.The apparatus containing a gas at low pressure. The positive ions are produced by the ionization of this gas. Consider a positive ion is produced; the direction of velocity of positive ions is perpendicular to the direction of B. The positive ion will move in a circular path with the force always directed toward the center of circular path. The magnetic force is responsible for the circular motion.

$$
\mathrm{F}_{\mathrm{B}}=\mathrm{qvBSin} \emptyset
$$

As this force is the centripetal force 
$\operatorname{qvBSin} \emptyset=\frac{m v^{2}}{r}$

$\mathrm{qBS} \operatorname{\phi in}=m w$

where, $\mathrm{w}=\frac{q B \operatorname{Sin} \emptyset}{m}=\frac{q B}{m} \quad\left(\varnothing=90^{\circ}\right)$

If $\mathrm{q}, \mathrm{B}$ and $\mathrm{m}$ are constant then $\mathrm{w}$ (angular velocity)is also constant. Now we will apply an electric field in a proportion that the radius of positive ion increases. Let us assume a point $\mathrm{P}_{1}($ Fig 1.1) where magnetic force acts on charged particles, is numerically equal to the force applied by electric field. $F_{B}$ is magnetic force and $\mathrm{F}_{\mathrm{e}}$ is force due to electric field.

$$
\mathrm{F}_{\mathrm{B}}=\mathrm{F}_{\mathrm{e}}
$$

$\mathrm{qvB}=\mathrm{qE}$

$\frac{v B}{r}=\frac{E}{r} \quad$ (multiply both side by $r$ ).

We get, $\mathrm{E}=\mathrm{rwB} \quad\left(\frac{v}{r}=w\right)$

Here $\mathrm{w}$ is constant and also magnetic field $\mathrm{B}$ is constant

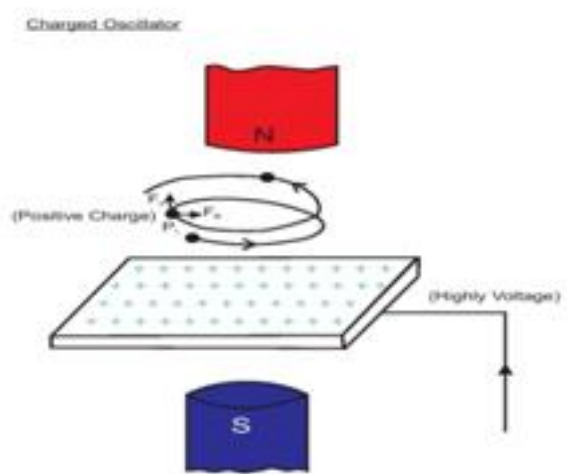

Figure 1. 3D Charge Oscillator

$\mathbf{E} \propto \boldsymbol{r}$ 
The more will be electric field more the radius will be increased. We know that when angular velocity is constant, by increasing radius the velocity also increases. Let the velocity increase be $\mathrm{v}_{0}$ by applying electric field $\mathrm{E}_{0}$ at point $\mathrm{P}_{1}$.

$P_{1}$ is a point where $F_{B}$ is equal to $F_{e}$

$\mathrm{F}_{\mathrm{B}}=\mathrm{F}_{\mathrm{e}}$

$\mathrm{qv}_{\mathrm{o}} \mathrm{B}=\mathrm{qE} \mathrm{E}_{0}$

$\mathrm{V}_{0} \mathrm{~B}=\mathrm{E}_{\mathrm{O}}$

To make the point $\mathrm{P}_{2}$ as point $\mathrm{P}_{1}$ where magnetic force is equal to electrostatic force.

$$
\mathrm{F}_{\mathrm{B}}=\mathrm{F}_{\mathrm{e}}
$$

$$
\mathrm{qv}_{1} \mathrm{~B}=\mathrm{qE} \mathrm{E}_{1}
$$

$$
\mathrm{v}_{1} \mathrm{~B}=\mathrm{E}_{0}
$$

Dividing (2) from(1)

$$
\frac{v_{1 B}}{V_{0} B}=\frac{E_{1}}{E_{0}}
$$

$$
\frac{E_{1}}{E_{0}}=\frac{V_{1}}{V_{0}}=\text { Constant }
$$

By applying electric field in this proportion the kinetic energy of positive ion increases. In fig (1.1) a metallic plate is used which applied electric field to the positive ion. This is a $3 \mathrm{D}$ charge oscillator, the positive ion will move in space.

\section{CONCLUSION}


When we increase the electric field, the kinetic energy of positive ion increases. The electric field is increased in a proportion. This is a 3D charge oscillator. In this charged oscillator dees are not required. In magnetic resonance accelerator alternating potential difference is applied both the end ${ }^{7}$. In these charged oscillator DC voltage are applied. It is suitable for accelerating heavy charged particles such as proton, positive ions.

\section{REFERENCES}

1. Livingston M.S. , Blewett J. , “Particle accelerators” McGraw-Hill-ISBN 978-1-114-44384-6 1969.

2. Alvarez L.W., "The design of proton linear accelerator”, Physical Review 1958; 4: 115-165.

3. Ginzton E.L. ,Hansen W.W. and Kennedy W.R. “ A linear electron accelerator”, Phys.Rev.1948; 19: 89-108.

4. Telnov V.I. , "The photon collider at ILC: status, parameter and technical problems", Acta Physics Poloncia B 2006; 37: 1049-1072

5. Accelerator Science, Publishing office of warsaw University of technology: http://www.wydawnictwopw.pl/index.php?s=wyniki\&rodz=7\&id=20

6. Editorial series on Accelerator Science and technology: ARIES, https://aries.web.cern.ch/content/editorial-series-accelerator-science-and-technology

7. Lawrence Earnest 0, Livingston M.Stanely, "The production of High speed Light Ions Without the use of High voltage”, Physical Review. American Physical society 1932; 40(1): 19-35. 